\title{
COVID-19 ¿riesgo real? Reflexiones de seguridad en un departamento de anatomía patológica
}

\author{
COVID-19 real risk? Safety reflections in a department of pathological anatomy
}

\author{
A Cecilia Gallegos Garza*
}

\begin{abstract}
Citar como: Gallegos GAC. COVID-19 iriesgo real? Reflexiones de seguridad en un departamento de anatomía patológica. Acta Med. 2020; 18 (4): 441-442. https://dx.doi.org/10.35366/97281
\end{abstract}

Las infecciones respiratorias de origen viral no son cosa nueva. Entre 30 y $50 \%$ de las neumonías adquiridas en la comunidad son de etiología viral. Las neumonías nosocomiales son causas conocidas de incremento en los días de internamiento, con frecuencia éstas también son de origen viral.

Los coronavirus son una familia de virus RNA no segmentados, encapsulados, responsables muy frecuentemente del resfriado común. La enfermedad por Coronavirus 19 o virus del síndrome respiratorio agudo severo coronavirus 2 (SARS-CoV-2) rápidamente se convirtió en una amenaza a la salud pública mundial.

El síndrome respiratorio agudo severo por Coronavirus 2 es una infección viral originada en Wuhan, China. Se transmite a través de minipartículas producidas al toser o estornudar principalmente o de manera indirecta al entrar en contacto con superficies contaminadas. Los signos y síntomas más frecuentes son prácticamente los mismos de otras infecciones respiratorias de origen viral, tos, fiebre, malestar general, etcétera. Los casos graves de COVID-19 que pueden ser fatales se deben a daño alveolar masivo, el cual lleva a falla respiratoria progresiva, sumado a la lesión directa al endotelio de capilares y la subsecuente trombosis relacionada con la reacción inflamatoria que dispara el virus. Puede presentarse en forma asintomática; sin embargo, estas personas, a pesar de no presentar manifestaciones, pueden transmitir la enfermedad. Cada

\footnotetext{
* Jefe de Departamento de Anatomía Patológica, Hospital Ángeles Pedregal.
}

Correspondencia:

A Cecilia Gallegos Garza

Correo electrónico: cecilia.gallegos@saludangeles.com

Aceptado: 04-06-2020.

www.medigraphic.com/actamedica infectado puede transmitir la enfermedad al menos a dos personas.

La detección de los casos de COVID-19 está principalmente enfocada en identificar a personas sintomáticas. Se realiza la prueba diagnóstica únicamente a quienes presenten tos, fiebre, disnea, con antecedente de viaje o convivencia con un paciente ya conocido. De esta manera, se subestima el número real de personas infectadas, personas con cuadros muy leves o asintomáticas.

La estrategia de detección debe cambiar, se deben instaurar protocolos para detectar el número real de personas infectadas, es decir, hacer más pruebas.

En relación con un departamento de anatomía patológica o patología quirúrgica dentro de una unidad hospitalaria, el riesgo de contagio, aunque menor si se compara con un servicio de urgencias, terapia intensiva, quirófano o consultorio, existe.

Se debe tener conciencia de que, con una sola persona, un solo paciente o un solo trabajador con síntomas respiratorios leves o infectado en fase asintomática que entre en contacto con las superficies y personas del área de recepción o de laboratorio, se puede transmitir la infección a todo el personal.

Se requiere establecer protocolos de prevención para proteger a todo el equipo de trabajo del Departamento de Patología. De acuerdo con la Organización Mundial de la Salud, los especímenes citológicos, quirúrgicos y de biopsias recibidos o recolectados deben ser considerados como potencialmente infecciosos. El equipo de trabajo del Departamento de Patología que recolecta, maneja y procesa los especímenes, debe seguir lineamientos rigurosos para evitar la infección y/o disminuir el riesgo de infección en el laboratorio.

Existe una amplia variedad de desinfectantes, sabemos que el SARS-CoV-2, así como otros como Coronavirus responsables del SARS (síndrome respiratorio agudo severo) y MERS (síndrome respiratorio de Medio Oriente) pueden 
permanecer activos en diversas superficies (metal, vidrio, madera, plástico, etcétera) durante más de nueve días. De igual manera, se sabe que con técnicas de sanitización relativamente sencillas, pueden ser inactivados de manera eficiente.

Los laboratorios de anatomía patológica pueden considerarse afortunados, dado que el propio proceso convencional de fijación en formol al 10\% e inclusión en parafina inactivan la gran mayoría de los virus. La exposición a formol al $10 \%$ a temperatura ambiente disminuye la capacidad infecciosa del virus en $90 \%$, en los casos de pacientes confirmados con COVID-19 se recomienda incrementar el tiempo de fijación a 48 horas, es decir, de 12 a 24 horas más de lo habitual. Además, el proceso de inclusión en parafina alcanza temperaturas de 60 a 65 ${ }^{\circ} \mathrm{C}$, de esta manera, el manejo de los cortes histológicos embebidos en parafina es seguro.

A pesar de esto, no se deben minimizar las medidas habituales de seguridad y el uso de equipo personal de seguridad para todos los trabajadores del departamento, histotecnólogos, asistentes de laboratorio, médicos anatomopatólogos y personal administrativo.

La realización de estudios histopatológicos transoperatorios a través de cortes congelados debe ser con extremas precauciones, considerando que este estudio sea indispensable para el manejo del paciente y que del resultado transoperatorio dependerá el manejo subsecuente. Si no cumple estos requisitos, no se recomienda realizar estudios histopatológicos por congelación.

Por ahora, mientras no se tengan pruebas rápidas de diagnóstico y detección de COVID-19, las medidas de higiene llegaron para quedarse. Todo paciente, independientemente de los síntomas o motivo de consulta, es potencialmente infectado. Se deben promover programas y protocolos que controlen la entrada de personas a los hospitales y servicios de salud. La presencia de personas en cualquier área del hospital debe ser limitada y controlada con medidas efectivas, instaurados por igual a pacientes, visitantes, proveedores, trabajadores de la salud y administrativos.

\section{LECTURAS RECOMENDADAS}

1. Guarner J. Three emerging coronaviruses in two decades, the story of SARS, MERS and now COVID-19. Am J Clin Pathol. 2020; 153 (4): 420-421.

2. Henwood AF. Coronavirus disinfection in histopathology. Jour of Histotech. 2020; 43 (2): 102-104. Available in: https://doi.org/10.1 080/01478885.2020.1734718.

3. Perlman S. Anotlher decade, another coronavirus. N Engl J Med. 2020; 382: 760-762.

4. Kampf G, Todt D, Pfaender S, Steinmann E. Persistence of coronaviruses on inanimate surfaces and its inactivation with biocidal agents. J Hosp Infect. 2020; 104 (3): 246-251. doi: 10.1016/j. jhin.2020.01.022.

5. Li R, Pei S, Chen B, Song Y, Zhang T, Yang W et al. Substantial undocumented infection facilitates the rapid dissemination of novel coronaviurs (SARS-CoV2). Science. 2020; 368 (6490): 489-493. doi: 10.1126/science.abb3221.

6. Klompas M. Coronavirus disease 2019 (COVID-19) protecting hospitals from the invisible. 2020: M20-0751. Ann Intern Med. doi: 10.7326/M20-0751.

7. Xu Z, Shi L, Wang Y, Zhang J, Huang L, Zhang C et al. Pathological findings of COVID-19 associated with acute respiratory distress syndrome. 2020; 8 (4): 420-422. Available in: https://doi. org/10.1016/52213-2600(20)30076-x. 